\title{
A preliminary look at negative constructions in South African Sign Language: Question-Answer clauses*
}

\author{
Kate Huddlestone \\ Department of General Linguistics, Stellenbosch University, South Africa \\ E-mail: katevg@sun.ac.za
}

\begin{abstract}
How negation is expressed by means of manual and/or non-manual markers has been described in a wide range of sign languages. This work has suggested a split between sign languages requiring a manual negative element in negative clauses (manual dominant sign languages) and those where a non-manual marker only can be used (non-manual dominant sign languages) (Zeshan 2006; 2004). To date there is only one published study on negation in SASL which describes SASL as a non-manual dominant language (De Barros and Siebörger 2016). However, Oomen and Pfau (2017) have recently indicated that such a typological split is too radical. They show that larger data sets are necessary to identify the range of expressions used within one sign language to express negation. This paper will contribute to this typological debate by considering some preliminary data from South African Sign Language (SASL), highlighting a particular construction, known as a polar Question-Answer clause, which is not generally mentioned in the literature on negation in sign languages. The paper will conclude with a reflection on the implications of these observations for a typology of negation in sign languages.
\end{abstract}

Keywords: negation, South African Sign Language, question-answer clause, non-manual marking

\section{Introduction}

Negation is a universal category of natural language (Dahl 1979: 80). All human languages make a distinction between affirmative and negative statements; however, negation remains marked in relation to affirmation (Horn 1989:156). For example, negation occurs far less frequently in discourse than affirmation (Miestamo 2006). The fact that negation is both marked and universal makes it one of the core topics in theoretically driven linguistic research. Such research has largely been focused on negation in spoken languages. However, in recent years the expression of sentential negation has been described in a wide range of sign languages, and has been shown to feature similar morphological and syntactic properties to those found in spoken languages. In addition, non-manual markers of negation such as headshakes or facial

\footnotetext{
* My sincere thanks to Anne Baker for the identification of the previously undescribed negative construction during initial transcription of the data and assisting in the analysis of the SASL sentences, as well as two anonymous reviewers for their constructive suggestions.
} 
expressions play a central role in sign languages and interact in interesting ways with manual negation elements and the syntactic structure of negative sentences (Pfau 2015, Quer 2012). Typological comparisons have, in fact, suggested a split between sign languages requiring a manual negative element in negative clauses (manual dominant sign languages) and those where a non-manual marker only can be used to express negation (non-manual dominant sign languages) (Zeshan 2006; 2004). Oomen and Pfau (2017: 44), however, argue that such a typological split is too radical, providing evidence from naturalistic corpus data of Sign Language of the Netherlands (NGT) for the claim that variation is attested within these two types.

Despite the growing body of research on the grammar of sign languages, and negation in sign languages in particular, South African Sign Language (SASL) remains an under-researched language. To date there is only one published study on negation in SASL which describes SASL as a non-manual dominant language (De Barros and Siebörger 2016). They describe an optional manual negator, occurring in post-verbal position, accompanied by a side-to-side headshake. They observe that the minimal scope of the non-manual marker is always over the matrix verb of the clause, and the maximum scope is over the verb phrase and the manual signs of negation. However, since that study made use of only two informants, one of whom was hearing, and only 39 instances of negation, it is questionable whether these observations are generalizable across all users of SASL and whether the typological characterisation of SASL is complete. Using a database (under construction) of spontaneous and elicited SASL material across several provinces we already have evidence that the negative structures in use are more diverse. This paper will discuss a particular construction, known as a polar Question-Answer clause (QAC), which is not generally mentioned in the literature on negation in sign languages, with a reflection on the implications of this observation for sign language typology.

This paper is organized as follows: in the next section, I provide a brief description of SASL. This is followed by a general description of negation in sign language and a section describing previous research on negation in SASL. The penultimate section gives a discussion of negative constructions in SASL, as observed in the data. In this section, I first provide a description of the data followed by a description of the observed polar QACs. The concluding section provides a brief discussion of the implications of these observations for sign language typology.

\section{South African Sign Language}

As mentioned above, SASL is an under-researched language with only minimal published research having been done on the syntax of SASL. Specifically, Aarons and Morgan (2000; 2003) examine the syntax of classifier predicates in SASL, while Vermeerbergen, van Herreweghe, Akach and Matabane (2007) look at the word order of SASL, comparing it with that of Flemish Sign Language (VGT).

According to the Deaf Federation of South Africa (DeafSA) ${ }^{1}$ approximately 600,000 South Africans are culturally and linguistically Deaf, meaning that they use a sign language in their daily lives. There is also a small number of hearing people, usually children of Deaf adults or professionals working closely with members of the Deaf community, who use SASL regularly

\footnotetext{
${ }^{1}$ https://www.facebook.com/pg/DeafSA-271471837806/about/?ref=page_internal
} 
and frequently. SASL is not yet one of the eleven official languages of South Africa, although the proposal that it should become the twelfth language is currently under official consideration $^{2}$. The constitution of the Republic of South Africa proclaims "Sign Language" to be one of the languages of South Africa that must be promoted and states that adequate conditions for its ongoing development and use must be created. According to the South African Schools Act of 1996, "[a] recognised Sign Language has the status of an official language for purposes of learning at a public school". However, SASL is not always used in schools for the deaf, either because there are not enough teachers who are fluent in SASL, or because the schools have policies of total communication or oralism (Aarons and Akach 1998; Storbeck, Magongwa and Parkin 2009; Storbeck et al. 2010). Furthermore, SASL as a school subject has only recently been introduced as part of the South African Curriculum and Assessment Policy Statement (CAPS), with its completion and approval as policy in July 2014.

As is the case in many countries, the history of sign language used in South Africa is closely linked to the development of schools for the deaf, irrespective of the schools' official policies on signing. As Aarons and Akach (1998: 5) point out, "Deaf people tend to seek out communities of other Deaf people, and the signing that has evolved around school centres tends to spread into Deaf communities, even if only some of their members have actually attended school". The history of deaf education in South Africa is extremely complex, largely due to the racial segregation imposed by Apartheid, but in general schools for white deaf pupils insisted on oralism, as 'speech' was perceived as the prestigious form of language (i.e., English and Afrikaans), whereas schools for the other races allowed some degree of signing (Aarons and Akach 1998; Storbeck et al. 2009; Storbeck et al. 2010). In the past it was hypothesised that as a result of apartheid education and social policies, different sign languages developed in South Africa (see Aarons and Akach 1998 for discussion). This hypothesis was most clearly articulated and accepted by the makers of the Dictionary of southern African Signs (Penn, Ogilvy-Foreman, Simmons, Anderson-Forbes \& Landman 1992). However Aarons and Akach (1998) have argued convincingly that this is not the case and now the emphasis seems to be more on the similarities between these variants than on the differences, so that in official documents only one "Sign Language" is mentioned. While there is considerable lexical variation in SASL (Ebersohn, van Niekerk, Huddlestone and Baker 2016), Vermeerbergen et al. (2007: 28) point out that in South Africa "[w]hat is noticeable is that Deaf people seem to manage very well to communicate with one another across racial and geographical boundaries".

\section{Sign language negation}

The realisation of negation in individual sign languages, as well as the attested typological variation across sign languages, has been described in a number of studies, both from a descriptive and a theoretical perspective (see Zeshan (2004; 2006) and Quer (2012) for detailed overviews). Sentential negation in the sign languages studied to date is expressed through the use of obligatory or optional manual signs, which usually occur in the form of independent particles. Sentential negation can also be expressed solely through non-manual markers. For example Catalan Sign Language (LSC) uses a manual negation particle, together with a nonmanual marker, as in example (1), but can also express negation with just the non-manual marker, a side-to-side headshake (glossed as 'neg', see the appendix for a list of abbreviations used in the transcriptions), as in example (2).

\footnotetext{
${ }^{2}$ https://www.timeslive.co.za/news/south-africa/2017-07-27-sign-language-could-become-the-12th-language
} 
(1) SANTI MEAT EAT NOT.

"Santi doesn't eat meat." (Baker, van den Bogaerde, Pfau and Schermer 2016: 136) ${ }^{3}$

(2) SANTI $\underline{\text { neg }}$

"Santi doesn't eat meat." (Baker et al. 2016: 137)

The position of the manual negation particle within the sentence can differ from sign language to sign language. For instance, in LSC, an SOV language, the particle appears in sentence-final position, as we see in example (1) above, while in American Sign Language (ASL), an SVO language, the negative particle occurs in preverbal position, as in example (3).

(3) JOHN NOT BUY HOUSE.

"John is not buying a house." (Baker et al. 2016: 136)

Interestingly, while typological studies on spoken languages indicate a strong tendency for negative particles to occur in pre-verbal position (Dahl 1979: 93), Zeshan (2004: 39) observes that, although basic word order has not been clearly established for many sign languages, there is a striking preference for post-predicate or clause-final position of negatives across sign languages, independently of word order typology.

Another respect in which sign languages may differ from one another is the scope of the nonmanual marker. For instance, while in LSC it is possible for the non-manual marker to occur only on the verb in transitive sentences, as in example (2) above, it is argued that this is impossible in ASL, and that the non-manual marker must spread onto the object in the absence of a manual marker of negation, as illustrated in example (4).

(4) JOHN BUY HOUSE.

"John is not buying a house." (Baker et al. 2016: 137) ${ }^{6}$

Sign languages like LSC and ASL, in which sentential negation is expressed by a combination of an optional manual particle and an obligatory non-manual marker, are called non-manual dominant languages, while languages in which the manual negation particle is obligatory are called manual dominant languages. Further typological variation with respect to negation is found in the form that the non-manual marker takes. While all sign languages studied to date make use of a headshake, some languages make use of an additional non-manual marker, namely a single backward head tilt (Baker et al. 2016: 138). Zeshan (2004: 12) observes that in addition to head movements, there are a large number of facial expressions that regularly occur in negative clauses. However, she notes that the status of facial expressions as grammatical markers is often questionable and, accordingly, they tend to be less obligatory and more variable than head movements. These include eyebrows lowered and/or drawn together/frowning, eyes

\footnotetext{
${ }^{3}$ https://benjamins.com/sites/z.199/video/6.38.1

${ }^{4}$ https://benjamins.com/sites/z.199/video/6.39

${ }^{5}$ https://benjamins.com/sites/z.199/video/6.38.2

${ }^{6}$ https://benjamins.com/sites/z.199/video/6.42a
} 
narrowed and/or squinted, lips spread or pursed or corners of the mouth pulled down, and nose wrinkling (Zeshan 2004: 13).

\section{Previous research on negation in South African Sign Language}

As noted above, De Barros and Siebörger (2016) represents the only published study on negation in SASL. According to their observations, negative sentences in SASL may contain an optional manual negator NOT, occurring in post-verbal position, accompanied by a side-toside headshake, with the following phonetic form: signed with two hands in the ] (B) ${ }^{7}$ handshape, fingers pointing forward; location in front of the signer in the neutral space ${ }^{8}$; palms face each other; hands rotate outwards so that palms end facing upwards (De Barros and Siebörger 2016: 8). They also observed the use of another manual negator, NOTHING, occurring in clause-final position, also accompanied by a side-to-side headshake, and with the following phonetic form: signed with two hands in the $\mathrm{M}(\mathrm{O})$ handshape; location in front of the signer in the neutral space; palms face each other; movement is a repeated side-to-side movement (De Barros and Siebörger 2016: 9). With respect to the non-manual marker of negation, De Barros and Siebörger (2016: 10) observed that the minimal scope of the side-to-side headshake was always over the matrix verb of the clause, and the maximum scope was over the verb phrase and the manual signs of negation ${ }^{9}$. Their conclusion is that the obligatory occurrence and fixed scope suggests that, in SASL, headshake negation is the chief clause negator. They further observed the presence of a facial expression, a "frown", which appeared frequently in various contexts, but always with other markers of negation and with varied scope. They conclude that facial expressions alone in SASL are not sufficient to signal negation and consider them to be affective expressions that may occur with manual signs and headshakes, possibly discourserelated (De Barros and Siebörger 2016:10). Following Pfau and Quer's (2002) analysis of sentential negation in German Sign Language (DGS), De Barros and Siebörger (2016: 11) apply a split-headed structure to SASL, arguing that the [+neg] feature, carried by the non-manual headshake, is morphological. They note that further research is needed to cross-check their analysis, given that the aim of their analysis was to provide a structure that may be subsequently refined and improved upon.

\section{Negative constructions in South African Sign Language: question-answer clauses}

While De Barros and Siebörger (2016) provide a useful starting point, it is clear from our preliminary observations, that negative structures in use in SASL are in fact more diverse than De Barros and Siebörger's description leads us to expect. These observed data exhibit variation with regard to the scope of the non-manual marking of negation. In this section I describe a particular construction that has been observed in both elicited material, collected for use as material for transcription exercises in an undergraduate course on sign language linguistics, and in spontaneous material in online YouTube videos. This section therefore presents some additional observations to supplement those of De Barros and Siebörger (2016) and to provide the next step on the path to providing a comprehensive account of negative constructions in SASL.

\footnotetext{
7 The handshape fonts are created by CSLDS, CUHK.

${ }^{8}$ Neutral space is located in front of the signer, with no place specification for body contact.

${ }^{9}$ However, it is not clear whether any of the observed negative sentences in the study contained post-verbal material (other than the manual negator when it was present). Following Vermeerbergen et al. (2007), De Barros and Siebörger (2016) assume that the word order of SASL is SOV or OSV.
} 


\subsection{Data}

The data on which the analysis is based comes firstly from an elicitation exercise in which two Deaf sign language informants from the Western Cape, signers A and B, were presented with a list of sentences which they were asked to sign in SASL. The sentences, including those containing negation, were recorded in two separate sessions, one for each informant, with a hearing camera person present. Sentence elicitation is generally avoided in sign language research as the methodology can easily result in distorted data (Palfreyman, Sagara and Zeshan 2015). As Zeshan (2006: 36) points out, "the signed utterances may end up resembling the stimulus sentences rather than being the natural and most common way of expressing the same idea in a particular sign language because there is often a substantial level of interference and unintended "word-by-word" translation". In order to mitigate this shortcoming, and the possibility that informants might resort to an artificial manual code of spoken language such as "Signed English" or "Signed Afrikaans", the written form of the sentences was presented in both Afrikaans and English. Both signers are fluent in written Afrikaans and English, although both admit to being more comfortable with Afrikaans. They were instructed to read both versions of each sentence to help them get an idea of the meaning that the sentence conveyed, and asked to imagine that they were signing to a Deaf person. As noted above, this material was elicited to provide example sentences for transcription exercises in a sign language linguistics course, and as such the observations which inform this paper are a by-product of the original elicitation sessions. The elicited data are supplemented by material found online in YouTube SASL teaching videos by signer C, Deaf, from the Western Cape and signers D, hearing, and E, Deaf, from Gauteng. Nine DTV online SASL teaching videos and one SASL grammar video, posted by the facilitators of the University of Cape Town Sign Language Classes, were examined, with four instances of negation recorded, two from signer $\mathrm{C}$, and one each from signers $\mathrm{D}$ and $\mathrm{E}$.

In total nine negative sentences were elicited from signers $\mathrm{A}$ and $\mathrm{B}$, none of which included a manual negation marker, but all of which were accompanied by a non-manual negation marker, a headshake (glossed as 'hs'), as illustrated in (5) below.

hs

\section{k-i-t-a INDEX 3 EAT SUGAR}

"Kita does not eat sugar."

[SASL - signer B]

Unlike in De Barros and Siebörger's (2016) data, the scope of the non-manual marker does not include the matrix verb, but occurs after the last signed element in the sentence ${ }^{10}$. This is the same for six of the other eight sentences, which are discussed in section 5.2. In two other sentences, sentences (15) and (17), also discussed in section 5.2, the non-manual marking of negation takes scope over the last element in the sentence.

In the online material, the negative sentence produced by signer D represented one of only two occurrences of a manual negator, with the headshake occurring over the manual negator, as illustrated in (6), below. The other manual negator occurred in sentence (14), given in section 5.2 , together with the non-manual marker. The negative sentence produced by signer E, illustrated in (7) below, reflects the structure observed by De Barros and Siebörger (2016),

\footnotetext{
${ }^{10}$ However sentence (5) does not display the SOV/OSV structure assumed by De Barros and Siebörger (2016), having an SVO word order.
} 
namely the non-manual headshake takes scope over the matrix verb, which occurs sentencefinally.
(6) MARRIED NO
"No, I'm not married."11
$[\mathrm{SASL}-$ signer D]
$\frac{\mathrm{hs}}{\text { (7) NO. SOMETHING ORDER WANT }}$
"No. I do not want to order something."12
$[\mathrm{SASL}-$ signer E]

Table 1 below presents a summary of the data, indicating the number of negative sentences examined, whether a manual negator was present, the scope of the non-manual negation and also an indication of the productivity of the polar Question-Answer (QAC) construction which will be discussed in the next section.

Table 1: Summary of the data

\begin{tabular}{|l|l|l|l|l|}
\hline Data source & $\begin{array}{l}\text { No. of } \\
\text { negative } \\
\text { sentences }\end{array}$ & $\begin{array}{l}\text { Presence of } \\
\text { manual } \\
\text { negator }\end{array}$ & Scope of non-manual negator & $\begin{array}{l}\text { Polar QAC } \\
\text { construction }\end{array}$ \\
\hline $\begin{array}{l}\text { Elicited } \\
\text { sentences } \\
\text { (signers A and } \\
\text { B) }\end{array}$ & 9 & - & $\begin{array}{l}\text { sentence-final (7) } \\
\text { over last signed element in } \\
\text { sentence (2) }\end{array}$ & 8 \\
\hline $\begin{array}{l}\text { SASL grammar } \\
\text { video (signer C) }\end{array}$ & 2 & 1 & $\begin{array}{l}\text { sentence-final (1) } \\
\text { over last signed element in } \\
\text { sentence (manual negator) (1) }\end{array}$ & 2 \\
\hline $\begin{array}{l}\text { DTV SASL } \\
\text { videos (signers } \\
\text { D and E) }\end{array}$ & 2 & 1 & $\begin{array}{l}\text { over last signed element in } \\
\text { sentence: manual negator (1); } \\
\text { matrix verb (1) }\end{array}$ & - \\
\hline
\end{tabular}

\subsection{Polar Question-Answer clauses}

Of the five SASL signers, three from the Western Cape and two from Gauteng, the three Western Cape signers use a construction, known in the literature as a "polar Question-Answer Clause" (QAC), productively (ten of the elicited/observed sentences). While this construction has been described, in terms of negation, for ASL (Caponigro and Davidson 2011; Davidson and Caponigro 2016), it is not generally mentioned in the literature on negation in sign languages, even in Zeshan $(2004 ; 2006)$ which examined negation in 38 sign languages. The utterance given in (8) is an example of a polar QAC in ASL, marked by raised eyebrows (glossed as 'br' in the ASL transcriptions). This construction is sometimes referred to as a 'rhetorical question' in the sign language community, however it differs from true rhetorical

\footnotetext{
${ }^{11}$ https://www.youtube.com/watch?v=3jH4YabB-Go

$12 \mathrm{https} / / / \mathrm{www}$.youtube.com/watch?v=8kN-MzIqtEM
} 
questions, which are not used to convey new propositional information, and are typically uttered without being followed by their answer ${ }^{13}$.

br

(8) INDEX 1 LAUGH, NO

"I was not laughing."
[ASL]

(Caponigro and Davidson 2011: 330)

According to Caponigro and Davidson (2011), QACs are syntactically declarative sentences, composed of an embedded interrogative clause (Q-constituent) followed by an embedded declarative clause (A-constituent), of which part is elided, and connected by a silent copula. In the case of polar QACs, the Q-consituent is a polar interrogative and the A-consituent is the answer particles YES or NO. In terms of their pragmatic function, Caponigro and Davidson (2011) argue that QACs are used to signal the (sub)-topic under discussion, or, in terms of Question Under Discussion (QUD) theory (Roberts 2012), the sub-QUD, and the related new information that is introduced in the discourse. They propose that QACs allow the signer to both make an implicit sub-QUD explicit, through the Q-consituent, and to answer it, through the A-consituent.

In the SASL data, we find utterances that look like polar interrogatives as they are accompanied by the polar interrogative non-manual marking of raised eyebrows (glossed as 're'). This is followed by a headshake (glossed as 'hs'), which conveys the negation, accompanied by lowered eyebrows (glossed as 'le'). Examples of this structure are given in (9)-(14) below. Only sentence (14) contains a manual marker of negation, with the headshake taking scope over this element.

hs

re le

(9) k-i-t-a INDEX 3 EAT SUGAR

"Kita does not eat sugar."

[SASL - signer A]

hs

re le

(10) LH: Cl human BUY HOUSE

RH: INDEX 3 MAN BUY HOUSE

"The man is not buying the house."

[SASL - signer B]

hs

re le

(11) MAN HOUSE BUY

"The man is not buying the house."

[SASL - signer A]

hs

re le

(12) INDEX 1 WOMAN INDEX 3 LIKE

"I do not like that woman."

[SASL - signer A]

\footnotetext{
${ }^{13}$ See Pfau and Steinbach (2013) for a brief discussion of so-called rhetorical questions, also referred to as whclefts, as they typically contain a $w h$-word.
} 
hs

re le

(13) SOUTH AFRICA SIGN LANGUAGE UNIVERSAL

"South African Sign Language is not universal." 14

[SASL - signer C]

re $\frac{\text { hs }}{\text { le }}$

(14) SOUTH AFRICA SIGN LANGUAGE ENGLISH SAME RELATIONSHIP NEG

"There is no one-to-one relationship between SASL and English." 15

[SASL - signer C]

This polar QAC structure is also evident in more complex structures involving coordination and conditional clauses, as illustrated in examples (15)-(18), although, as raised eyebrows are also used to indicate a conditional, there is possible interference in sentences (17) and (18) (Pfau and Steinbach 2016).

(15) LH: $\quad \mathrm{Cl}$ human

RH: b-e-l-a INDEX 3 WANT STUDY ENGLISH TIME

"Bela wants to learn English but she does not have time."

[SASL - signer B]

hs

re le

(16) b-e-l-a INDEX 3 WANT ENGLISH STUDY BUT TIME HAVE

"Bela wants to learn English but she does not have time."

[SASL - signer A]

hs

(17)

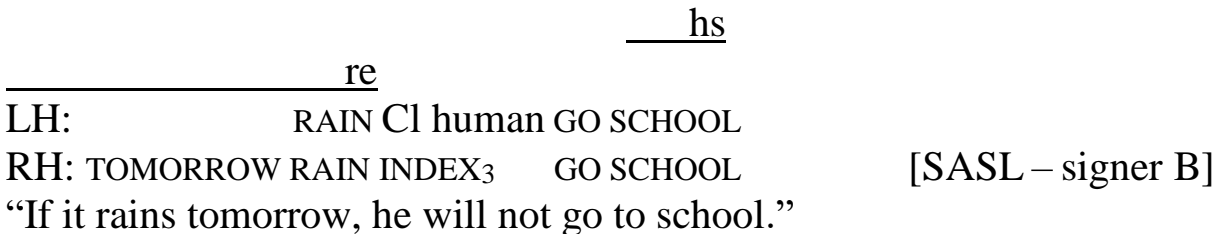

hs

re le

(18) TOMORROW INDEX 3 RAIN SCHOOL GO [SASL - signer A]

"If it rains tomorrow, he will not go to school."

The data clearly indicate that the headshake occurs at the end of the clause, with possible overlap on the last signed element in the clause, as illustrated in examples (14), (15) and (17). Contrary to De Barros and Siebörger (2016), we found no evidence of minimal scope of the non-manual marker over the finite verb, and we found only one instance of a manual negator.

\section{Implications for the typology of negation in sign languages}

The new data presented in this paper indicate that, contrary to previous descriptions of negation in SASL, non-manual marking of negation does not necessarily take scope over the matrix verb,

\footnotetext{
${ }^{14} \mathrm{https}: / / \mathrm{www}$.youtube.com/watch?v=sAgwtMFFDqM

$15 \mathrm{https} / / / \mathrm{www}$.youtube.com/watch? $\mathrm{v}=$ sAgwtMFFDqM
} 
although word order may be a confounding factor. Instead, non-manual marking appears to occur utterance-finally, with possible overlap on the last-signed element in the clause. This ties in with Oomen and Pfau's (2017) observation that there is considerable variation within the manual/non-manual negation typological split. Furthermore, negative constructions in the sample of elicited SASL negative sentences, as well as in the one online YouTube video, take the form of a polar QAC, a construction not previously discussed in relation to the realisation of negation in sign languages. Given that in ASL QACs are dispreferred in "out of the blue" contexts (Caponigro and Davidson 2011: 359), it remains to be explained why such a construction appears to be the default option for expressing negation in elicited sentences, although its use in the YouTube video does point to it being an unmarked construction. Further research, including naturalistic data, should indicate how widely used this construction is and whether there are restrictions on its context of use.

\section{References}

Aarons, D. and P. Akach. 1998. South African Sign Language - one language or many? A sociolinguistic question. Stellenbosch Papers in Linguistics, 31: 1-28.

Aarons, D. and R. Morgan. 2000. The interaction of Classifiers and Syntax in South African Sign Language. Stellenbosch Papers in Linguistics, 33: 1-20.

Aarons, D. and R. Morgan. 2003. Classifier predicates and the creation of multiple perspectives in South African Sign Language. Sign Language Studies, 3(2): 12-156.

Baker, A.E., B. van den Bogaerde, R. Pfau and T. Schermer (eds). 2016. The linguistics of sign languages: an introduction. Amsterdam: Benjamins.

Caponigro, I. and K. Davidson. 2011. Ask, and tell as well: Question-Answer Clauses in American Sign Language. Natural Language Semantics, 19(4): 323-371.

Dahl, Ö. 1979. Typology of sentence negation. Linguistics, 17(1-2): 79-106.

Davidson, K. and I. Caponigro. 2016. Embedding polar interrogative clauses in American Sign Language. In A. Herrmann, R. Pfau and M. Steinbach (eds). A matter of complexity: subordination in sign languages. Berlin: Mouton de Gruyter. pp.151-181.

De Barros, C. and I. Siebörger. 2016. Sentential negation in South African Sign Language: A case study. Literator, 37(2): 1-13.

Ebersohn, D., A. van Niekerk, K. Huddlestone and A.E. Baker. 2016. Charting lexical variety in SASL. Paper presented at the Joint LSSA/SAALA/SAALT Conference 2016. University of the Western Cape, Cape Town.

Horn, L. 1989. A natural history of negation. Chicago: University of Chicago Press.

Miestamo, M. 2006. Negation. In J-O. Östman and J. Verschueren (eds.). Handbook of Pragmatics. Amsterdam: Benjamins. pp.1-23. 
Oomen, M. and R. Pfau. 2017. Signing not (or not): a typological perspective on standard negation in Sign Language of the Netherlands. Linguistic Typology, 21(1): 1-51.

Palfreyman, N., K. Sagara and U. Zeshan. 2015. Methods in carrying out language typological research. In E. Orfanidou, B. Woll and G. Morgan (eds). Research Methods in Sign Language Studies. Chichester, UK: Wiley. pp.173-192.

Penn, C., D. Ogilvy-Foreman, D. Simmons, M. Anderson-Forbes and K. Landman. 1992. Dictionary of southern African signs for communicating with the deaf: Volume 1. Pretoria: Human Sciences Research Council.

Pfau, R. 2015. The grammaticalization of headshakes: from head movement to negative head. In A. Smith, G. Trousdale and R. Waltereit (eds). New directions in grammaticalization research. Amsterdam: Benjamins. pp. 9-50.

Pfau, R. and J. Quer. 2002. V-to-Neg raising and negative concord in three sign languages. Rivista di Grammatica Generativa, 27: 73-86.

Pfau, R. and M. Steinbach. 2016. Complex sentences in sign languages - modality, typology, discourse. In A. Herrmann, R. Pfau and M. Steinbach (eds). A matter of complexity: subordination in sign languages. Berlin: Mouton de Gruyter Mouton. pp.151-181.

Quer, J. 2012. Negation. In R. Pfau, M. Steinbach and B. Woll (eds). Sign language: an international handbook. Berlin: Walter de Gruyter. pp.316-339.

Roberts, C. 2012. Information structure in discourse: Towards an integrated formal theory of pragmatics. Semantics \& Pragmatics, 5: 1-69.

Storbeck, C., L. Magongwa and I. Parkin. 2009. Education of the Deaf in South Africa. In D. Moores and M. Miller (eds). Deaf people around the world: educational and social perspectives. Washington, DC: Gallaudet University Press. pp.133-144.

Storbeck, C., D. Martin, I. Parkin, L. Magongwa, B.P. Druchen, M. Batchelor, G. McIlroy, D. de Villiers, N. Captieux-Bhana, L. Rasebopye, D. Rasebopye, S. Krige-Henderson, F. Krige, A. Louw, T. Surtees, A.L. Smit, R. Cox and M. Henderson. 2010. South African Deaf education and the Deaf community. American Annals of the Deaf, 155(4): 488-518.

Vermeerbergen, M., M. van Herreweghe, P. Akach and E. Matabane. 2007. Constituent order in Flemish Sign Language (VGT) and South African Sign Language (SASL): a cross-linguistic study. Sign Language \& Linguistics, 10(1): 23-54.

Zeshan, U. 2004. Hand, head, and face: Negative constructions in sign languages. Linguistic Typology, 8(1): 1-58.

Zeshan, U. (ed.). 2006. Interrogative and negative constructions in sign languages. Nijmegen: Ishara Press. 


\section{Appendix: List of abbreviations}

br - "brow raise"; equivalent to "raised eyebrows"

$\mathrm{Cl}$ - "classifier"

hs - "head shake"

le - "lowered eyebrows"

LH - left hand

neg - "negation"; equivalent to "head shake"

re - "raised eyebrows"

$\mathrm{RH}$ - right hand 